\title{
Development of novel arginase inhibitors for therapy of endothelial dysfunction
}

\section{Jochen Steppan, Daniel Nyhan and Dan E. Berkowitz*}

Department of Anesthesiology and Critical Care Medicine, The Johns Hopkins Medical Institutions, Baltimore, MD, USA

\section{Edited by:}

Rudolf Lucas, Medical College of Georgia, USA

\section{Reviewed by:}

Rudolf Lucas, Medical College of Georgia, USA

Matthias Clauss, Indiana University, USA

\section{*Correspondence:}

Dan E. Berkowitz, Department of Anesthesiology and Critical Care

Medicine, The Johns Hopkins

University School of Medicine, 1800

Orleans Street, Baltimore, MD 21287, USA

e-mail:dberkow1@jhmi.edu
Endothelial dysfunction and resulting vascular pathology have been identified as an early hallmark of multiple diseases, including diabetes mellitus. One of the major contributors to endothelial dysfunction is a decrease in nitric oxide (NO) bioavailability, impaired NO signaling, and an increase in the amount of reactive oxygen species (ROS). In the endothelium NO is produced by endothelial nitric oxide synthase (eNOS), for which L-arginine is a substrate. Arginase, an enzyme critical in the urea cycle also metabolizes L-arginine, thereby directly competing with eNOS for their common substrate and constraining its bioavailability for eNOS, thereby compromising NO production. Arginase expression and activity is upregulated in many cardiovascular diseases including ischemia reperfusion injury, hypertension, atherosclerosis, and diabetes mellitus. More importantly, since the 1990s, specific arginase inhibitors such as $N$-hydroxy-guanidinium or N-hydroxy-norL-arginine, and boronic acid derivatives, such as, 2(S)-amino-6-boronohexanoic acid, and $S$-(2-boronoethyl)-L-cysteine, that can bridge the binuclear manganese cluster of arginase have been developed. These highly potent and specific inhibitors can now be used to probe arginase function and thereby modulate the redox milieu of the cell by changing the balance between NO and ROS. Inspired by this success, drug discovery programs have recently led to the identification of $\alpha-\alpha$-disubstituted amino acid based arginase inhibitors [such as (R)-2-amino-6-borono-2-(2-(piperidin-1-yl)ethyl)hexanoic acid], that are currently under early investigation as therapeutics. Finally, some investigators concentrate on identification of plant derived compounds with arginase inhibitory capability, such as piceatannol-3'-O- $\beta-D-$ glucopyranoside (PG). All of these synthesized or naturally derived small molecules may represent novel therapeutics for vascular disease particularly that associated with diabetes.

Keywords: endothelium, endothelial dysfunction, arginase, L-arginine, nitric oxide synthase, reactive oxygen species, diabetes mellitus

\section{NITRIC OXIDE AND ITS REGULATION BY ARGINASE}

The endothelium plays a major role in cardiovascular physiology. The intact structure and integrity is vital for endothelial cells in order to fulfill their role separating blood flow from surrounding tissues and ensuring an anti-thrombogenic surface. Previously only known of as a passive barrier between those two, the endothelium is now considered a main hub for regulating vascular tone, hemostasis, immune function, structure, smooth muscle cell proliferation, and migration. The combined amount of surface area of the endothelium can reach up to $350 \mathrm{~m}^{2}$ in total (1). Endothelial dysfunction has been identified as an early harbinger of multiple diseases and resulting vascular pathology. One of the major contributors to endothelial dysfunction is a decrease in nitric oxide (NO) bioavailability, impaired NO signaling, and an increase in the amount of reactive oxygen species (ROS). NO is not only a potent vasodilator and essential in regulating vascular tone and blood pressure, but it also contributes to the regulation of hemostasis, platelet, and leukocyte adhesion as well as vascular smooth muscle cell proliferation. It is freely diffusible with a half-life of just a few seconds prior to its conversion into nitrates and nitrites that are ultimately excreted. NO is synthesized by nitric oxide synthase (NOS), a family of P450 mono-oxygenase-like enzymes which exist in one of three isoforms: nNOS or NOS-1 (neuronal NOS in the central nervous system, skeletal muscle, and pancreas), iNOS or NOS-2 (inducible NOS in activated macrophages, heart, liver, and smooth muscle cells), and eNOS or NOS-3 (endothelial NOS in the endothelium, brain, and epithelium). In the endothelium NO is produced by eNOS (endothelial NOS), which uses L-arginine as a substrate after activation by either chemical agonists or mechanical forces (shear stress). The process of NO synthesis involves firstly the oxidation of arginine to NG-hydroxy-L-arginine (NHA) using nicotinamide adenine dinucleotide phosphate (NADPH) and $\mathrm{O}_{2}$ catalyzed by NOS (2). The second step involves the production of NO when NHA is converted to L-citrulline via NOS. The actions of NOS are accelerated by the cofactors flavin adenine dinucleotide (FAD), flavin mononucleotide (FMN), and tetrahydrobiopterin (BH4). In the absence of its substrate L-arginine or its cofactor BH4, eNOS uncouples and produces ROS, making it one of the four major enzymes involved in the production of vascular ROS. (The others are xanthine oxidase, $\mathrm{NADH} / \mathrm{NADPH}$, the mitochondrial electron transport chain, and eNOS). NOS uncoupling is an important contributor to endothelial dysfunction and plays a crucial role in the cardiovascular phenotype. Arginase, a critical urea cycle enzyme, 
also utilizes L-arginine. It thereby directly competes with eNOS for their common substrate L-arginine and constrains its availability to eNOS, compromising NO production and increasing the production of ROS by NOS uncoupling (3-5). Arginase, which is present in two isoforms (arginase I in the liver and arginase II extrahepatic) catalyzes the final step of the urea cycle yielding Lornithine and urea from L-arginine. Arginase II appears to be the predominant isoform in human endothelial cells (6) and is highly compartmentalized. There appear to be at least three distinct pools of $\mathrm{L}$-arginine that are spatially confined and regulated by different transporters and enzymes $(7,8)$. Thus, local concentrations of Larginine in microdomains in which NOS and/or arginase might be located may be limiting for NOS isoforms. This concept of the L-arginine paradox is found in the mammalian organism by which $\mathrm{L}$-arginine concentrations by far exceed $K_{\mathrm{m}}$ values of NOS. Consequently, additional L-arginine should not augment nitric oxide formation. In vivo however, increasing the plasma concentration of L-arginine has repeatedly been shown to increase NO production (4). The three existing pools of arginine within the cell are (1) a freely exchangeable pool (pool I) with extracellular Larginine that is regulated by the cationic transporter (CAT-1) and depleted by exchanging the pool with cationic amino acid lysine, (2) a non-freely exchangeable pool (pool II) with extracellular Larginine that cannot depleted by L-lysine, and (3) extracellular L-arginine pools (pool III) present in endothelial cells and mitochondria in which arginase II modulates NO synthesis through a non-freely exchangeable L-arginine pool (9). According to recent paradigms, the not freely exchangeable L-arginine pool II is composed of two cytosolic microdomains. The major function of pool IIA appears to be the result of citrulline recycling and conversion to arginine by a combined reaction of argininosuccinate synthetase and argininosuccinate lyase (10). The remaining L-arginine pool IIB, which is mainly used by mitochondria, is composed of $\mathrm{L}^{-}$ arginine gained by protein breakdown and cannot be depleted by neutral amino acids such as histidine. Arginase expression and activity is upregulated in many diseases including ischemia reperfusion injury (in the heart, lung, and kidneys), hypertension, atherosclerosis, aging, diabetes mellitus, erectile dysfunction, pulmonary hypertension, and aging. Furthermore it can be induced by lipopolysaccharide (LPS), TNF $\alpha$, interferon $\gamma, 8$-bromo-cGMP, and hypoxia (11-14). It has been shown repeatedly that both arginase isoforms are capable of reciprocally regulating NO production $(3,4,15)$. More importantly the development of specific arginase inhibitors like $N$-hydroxy-guanidinium or boronic acid derivatives, such 2(S)-amino-6-boronohexanoic acid, and $S$-(2boronoethyl)-L-cysteine (BEC) can now be used to probe arginase function (16). This development in the 1990s allowed the selective inhibition of arginase in the laboratory and thereby the modulation of the substrate availability for NOS and its end product NO (17-19).

\section{ARGINASE STRUCTURE, ENZYMATIC FUNCTION, AND INHIBITOR DESIGN}

The first step toward the generation of arginase inhibitors was the determination of the crystal structure of arginase and its active site. Dr. Christianson and his laboratory team from the University of Pennsylvania first demonstrated the binuclear manganese cluster required for catalysis at the active side of rat arginase using X-ray crystallography (20). Successive studies determined the structures of human arginase I (21) and human arginase II (22), both of which contain almost identical metal clusters and active site configurations, this similarity makes it very difficult to develop inhibitors that are specific for one arginase isoform. At the active site, L-ornithine and urea are formed by the collapse of a tetrahedral intermediate that forms after the addition of a hydroxide ion to the $\mathrm{L}$-arginine guanidinium group in the binuclear manganese cluster (Figures 1A,B).

The first group of arginase inhibitors consisted of the boronic acid analogs of $\mathrm{L}$-arginine (2) $S$-amino-6-hexanoic acid $(\mathrm{ABH})$ and $S$-2-BEC both of which inhibit the catalytic activity of arginase $(16,23,24)$. As both contain trigonal planar boronic acid moieties instead of a trigonal planar guanidinium group, found in $\mathrm{L}$-arginine, binding to the active site of arginase results in a nucleophilic attack of the boron atoms by the metal-bridging ion, resulting in a tetrahedral boronate ion (18). This reaction is identical to the creation of a tetrahedral intermediate by nucleophilic attack of hydroxide ions at the guanidinium group of $\mathrm{L}$-arginine and has been confirmed by crystallographic structure determination $(18,22,24)$ (Figures 1C,D). The ability of the boronic side chains of $\mathrm{ABH}$ and $\mathrm{BEC}$ to bind the active side chain of arginase is 50,000 times stronger than the binding of comparable amino acids, aldehyde, or tetrahedral sulfonamide, both of which mimic the tetrahedral intermediate in the arginase mechanism $(22,25) . \mathrm{ABH}\left[K_{\mathrm{i}}=0.11 \mu \mathrm{M}\right.$ for arginase $\mathrm{I}$ and $K_{\mathrm{i}}=0.25 \mu \mathrm{M}$ (at $\mathrm{pH}$ of 7.5$)$ for arginase II $(26,27)]$ and BEC $\left[K_{\mathrm{i}}=0.4-0.6 \mu \mathrm{M}\right.$ for arginase I and $K_{\mathrm{i}}=0.31 \mu \mathrm{M}$ (at $\mathrm{pH}$ of 7.5) for arginase II (18)] are therefore specific inhibitors of arginase as they are closely matched to the metal-bridging hydroxide ion in the active site of arginase.

Another category of arginase inhibitors, that is mainly represented by $N$-hydroxy-L-arginine (NOHA) and $N$-hydroxynor-L-arginine (nor-NOHA), is characterized by $N$-hydroxyguanidinium side chains $(25,28-30)$. Analysis of the enzyme structure by X-ray crystallography reveals that both NOHA and nor-NOHA inhibit arginase by displacing the metal-bridging hydroxide ion of arginase with their $N$-hydroxy group (31). Based on this mechanism, both amino acids inhibit arginase activity with nor-NOHA being a more potent inhibitor $\left(K_{\mathrm{i}}=500 \mathrm{mM}\right.$ for norNOHA vs. $K_{\mathrm{i}}=10 \mu \mathrm{M}$ for NOHA) $(28,30)$ and with both being less specific than the boronic acid derivates $\mathrm{BEC}$ and $\mathrm{ABH}$ [for nor-NOHA the $K_{\mathrm{i}}$ values for arginase I and arginase II are 500 and $50 \mathrm{nM}$, respectively (32)].

Recent efforts now concentrate on expanding the range of arginase inhibitors based on a structure based design program, translating ABH's mechanism of action into new compounds $(33,34)$. Identifying the $\alpha$-position of $\mathrm{ABH}$ as a target for site substitution, a tertiary amine linked via a two-carbon chain improves the ability of $\mathrm{ABH}$ to inhibit both arginase $\mathrm{I}$ and arginase II (35). X-ray crystallography demonstrates a close contact between nitrogen and the carboxylic side chain of Asp 181 (arginase I) and Asp 200 (arginase II) at the active site (Figure 2) (35). This has led to the discovery of $(R)$-2-amino-6-borono2-(2-(piperidin-1-yl)ethyl)hexanoic acid (compound 9) a small 

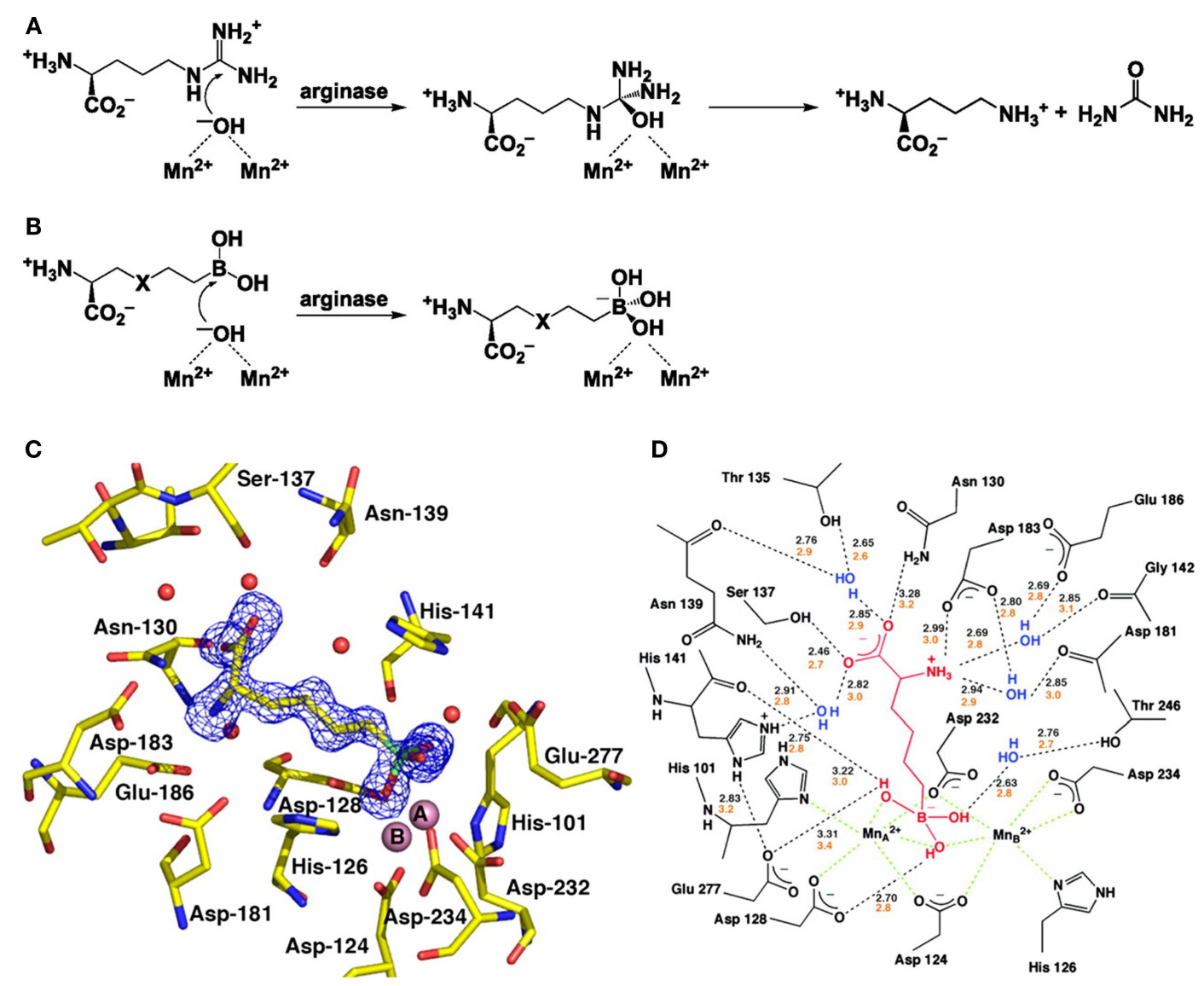

FIGURE 1 | Structure and function of arginase and the interaction with BEC. (A) The formation of L-ornithine and urea from L-arginine by arginase. (B) The reaction of the boronic acid analogs of L-arginine, 2(S)-amino-6hexanoic acid $(\mathrm{ABH})(\mathrm{X}$ representing $\mathrm{CH} 2$ ) and $\mathrm{S}$-(2-boronoethyl)-L-cysteine
(BEC) (X representing S). (C) Electron density map of $\mathrm{ABH}$ bound to human arginase I. (D) A schematic showing the enzyme-inhibitor hydrogen bond (black dashed lines) and metal coordination interactions (green dashed lines). With kind permission from Santhanam et al. (55). molecule that has shown efficacy in the attenuation of myocardial reperfusion injury (33). Compound 9 contains a piperidine linked to the $\alpha$-carbon by a two-carbon aliphatic chain at the $\alpha$-position. This results in the formation of new throughwater hydrogen bonding interaction with Asp 181 and Asp 183 (arginase I), providing a roughly sixfold increase in potency compared to $\mathrm{ABH}$. Co-crystallizing compound 9 with arginase II yields a similar, albeit weaker interaction of the through-water contacts between the piperidine ring nitrogen atom and Asp 200 and Asp 202 (arginase II: IC50 509 nM vs. arginase I: IC50 $223 \mathrm{nM})$.

In a parallel approach to finding new and improved inhibitors of arginase, some investigators have concentrated on characterizing a plant derived compound with the ability to inhibit arginase $(36,37)$. It has been demonstrated that piceatannol-3' $-O$ $\beta$-D-glucopyranoside (PG), an important component of rhubarb extract has, antioxidant effects (38), Woo et al. tested the ability of this extract to act as an arginase inhibitor (36). They were able to demonstrate that PG inhibits arginase I and arginase II activity and increased nitric oxide production in a dose-dependent manner. In their experiments $P G$ proved to be a non-specific arginase inhibitor with an IC50 value of $11.22 \mu \mathrm{M}$ (arginase I) and $11.06 \mu \mathrm{M}$ (arginase II) respectively (36). Furthermore they were able to extend their studies by demonstrating that PG improves endothelial dysfunction via eNOS activation in a rodent model of hyperlipidemia (39).

This search for a new plant derived arginase II specific inhibitor has very recently been extended by screening hundreds of plant extracts for potential targets (37). This investigation yielded a methanol extract of Scutellaria indica, that has the ability inhibit arginase II. Following multiple additional fractionations, and repeated column chromatography, the group was able to isolate eight different compounds from the extract. One of the compounds (compound 1, flavan type) has been previously unknown while the remaining seven compounds (compound 2-8) have been described earlier. Arginase II activity was inhibited by two of the eight compounds (compound number 3 and 5) with an IC50 of 25.1 and $11.6 \mu \mathrm{M}$, respectively (37). They authors did not test the capability of the extract or compounds to inhibit arginase I, nor did they investigate the underlying mechanism of arginase II inhibition. 


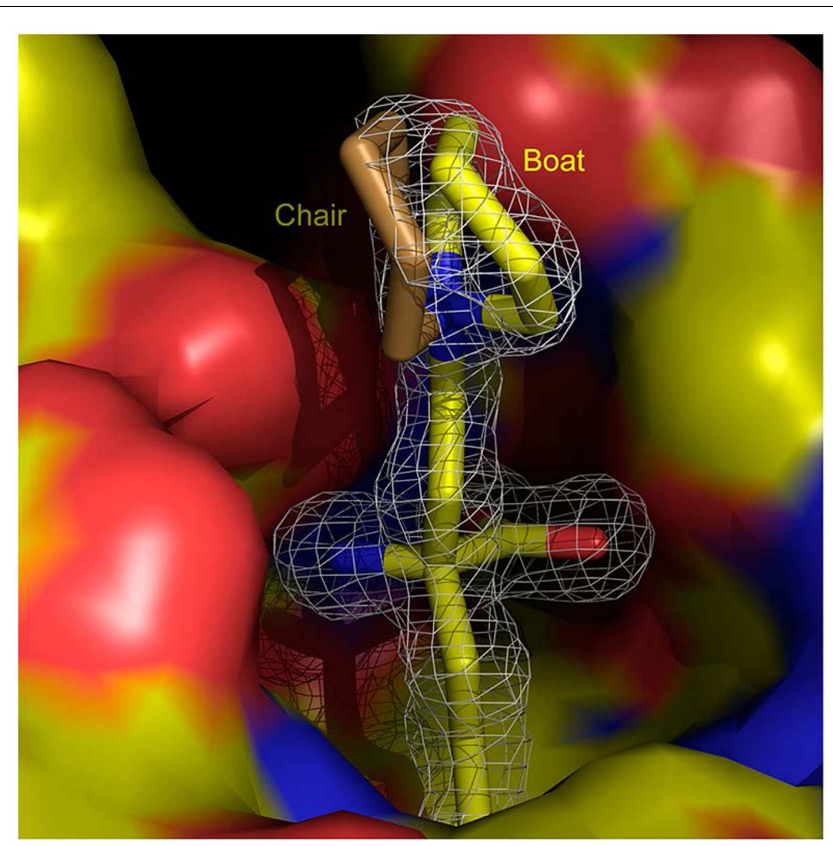

FIGURE 2 | (R)-2-amino-6-borono-2-(2-(piperidin-1-yl)ethyl)hexanoic acid) and arginase 1. Structure of (R)-2-amino-6-borono-2-(2-(piperidin-1-yl) ethyl)hexanoic acid) at the active site of arginase I (surface colored according to charge), shown superimposed with a difference map calculated without the inhibitor model contoured at 3 RMS (white contours). With kind permission from Ref. (33).

\section{IMPLICATIONS OF INHIBITORS IN DIABETES MELLITUS}

Diabetes mellitus has long been shown to be a disease tightly associated with endothelial dysfunction (40). Recent data suggests that metabolic degradation of L-arginine is directly involved in the L-arginine enhanced insulin-stimulated glycogen synthesis (41). Furthermore, hyperglycemia and the hemoglobin A1C levels correlate to arginase activity, with arginase activity being increased in type 2 diabetic subjects with impaired NOS activity (42-44). These higher arginase activity levels could be a result of reduced insulin action and increased protein catabolic processes in diabetic subjects (45). Consequently, insulin treatment reverses increased arginase activity and mRNA levels to close to control values (46). In addition to the effect of arginase in the endothelium of diabetic

\section{REFERENCES}

1. Pries AR, Secomb TW, Gaehtgens P. The endothelial surface layer. Pflugers Arch (2000) 440(5):653-66. doi: $10.1007 / \mathrm{s} 004240000307$

2. Woodward JJ, Chang MM, Martin NI, Marletta MA. The second step of the nitric oxide synthase reaction: evidence for ferric-peroxo as the active oxidant. J Am Chem Soc (2009) 131(1):297-305. doi:10. 1021/ja807299t

3. Berkowitz DE, White R, Li D, Minhas KM, Cernetich A, Kim S, et al. Arginase reciprocally regulates nitric oxide synthase activity and contributes to endothelial dysfunction in aging blood vessels. Circulation (2003) 108(16): 2000-6. doi:10.1161/01.CIR. 0000092948.04444.C7

4. Steppan J, Ryoo S, Schuleri KH, Gregg C, Hasan RK, White AR, et al. Arginase modulates myocardial contractility by a nitric oxide synthase 1-dependent mechanism. Proc Natl Acad Sci $U S$ A (2006) 103(12):4759-64. doi:10. 1073/pnas.0506589103

5. White AR, Ryoo S, Li D, Champion HC, Steppan J, Wang D, et al. Knockdown of arginase I restores

patients, arginase is also present and active in human islets cells of the pancreas, where arginase activity regulates the generation of NO (47).

The molecular mechanism of glucose-induced upregulation of arginase activity appears to involve small $G$ proteins. In fact, the Rho kinase inhibitor Y-27632 as well as a HMG-coenzyme reductase inhibitor (statin) blunt the upregulation of the enzyme as well as ROS production under these conditions. Therefore, statins, which are known to inhibit the Rho/Rock pathway, reduce vascular events in patients with diabetes in part by a mechanism that involves inhibition of arginase activation $(48,49)$. Moreover, studies show that diabetes-induced impairment of vasorelaxation is correlated with increases in ROS, arginase activity, and arginase expression in the aorta. A treatment regime with simvastatin or L-citrulline is able to blunt these effects and acute treatment of diabetic coronary arteries with arginase inhibitors has been shown to reverse the impaired vasodilation to acetylcholine (50). This is likely due to the upregulation of arginase I in coronary arterioles of diabetic patients, which contributes to reduced NO production and consequently diminished vasodilation (51). Thus, endothelial dysfunction in diabetes may be caused, at least partially, by reduced L-arginine availability for eNOS. Given both preclinical data from animal models, early but provocative human data, as well as potent small molecule inhibitor drug candidates, arginase promises to be an exciting, novel target for therapy in diabetic vasculopathy, a scourge for which there is currently little effective treatment. However caution is advised in selectively inhibiting arginase isoforms in macrophages. The inflammatory phenotype M1 macrophages (Th1 immune response) mainly expresses arginase II, while the profibrotic and repair phenotype M2 (alternatively activated macrophage, Th2 cytokine response) mainly expresses arginase I (52). Therefore selective inhibition of arginase I might lead to an expansion of the M1 phenotype, which could aggravate iNOS mediated inflammatory effects (53), while selective arginase II inhibition might enhance the profibrotic response of alternatively activated ornithine producing macrophages with potential deleterious effects on vessels and other organs (54).

\section{ACKNOWLEDGMENTS}

The authors wish to thank all members of the Shoukas-Berkowitz lab for their support in this project and Mary Ann Anderson for her secretarial assistance. Funding: Dan E. Berkowitz R01 HL089668.

NO signaling in the vasculature of old rats. Hypertension (2006) 47(2):245-51. doi:10.1161/01.HYP. 0000198543.34502.d7

6. Ming XF, Barandier C, Viswambha$\operatorname{ran} \mathrm{H}$, Kwak BR, Mach F, Mazzolai L, et al. Thrombin stimulates human endothelial arginase enzymatic activity via RhoA/ROCK pathway: implications for atherosclerotic endothelial dysfunction. Circulation (2004) 110(24):3708-14. doi:10.1161/01.CIR.0000142867. 26182.32

7. Nawrath H, Wegener JW, Rupp J, Habermeier A, Closs EI. Voltage dependence of L-arginine transport by hCAT-2A and hCAT2B expressed in oocytes from Xenopus laevis. Am J Physiol Cell Physiol (2000) 279(5): C1336-44.

8. Rotmann A, Closs EI, Liewald JF, Nawrath H. Intracellular accumulation of L-Arg, kinetics of transport, and potassium leak conductance in oocytes from Xenopus laevis expressing hCAT-1, hCAT-2A, and hCAT-2B. Biochim Biophys Acta (2004) 1660(1-2): 138-43. doi:10.1016/j.bbamem. 2003.11.009 
9. Topal G, Brunet A, Walch L, Boucher JL, David-Dufilho M. Mitochondrial arginase II modulates nitric-oxide synthesis through nonfreely exchangeable L-arginine pools in human endothelial cells. J Pharmacol Exp Ther (2006) 318(3):1368-74. doi:10.1124/jpet. 106.103747

10. Solomonson LP, Flam BR, Pendleton LC, Goodwin BL, Eichler DC. The caveolar nitric oxide synthase/arginine regeneration system for NO production in endothelial cells. J Exp Biol (2003) 206(Pt 12):2083-7. doi:10.1242/jeb.00361

11. Koga T, Koshiyama Y, Gotoh T, Yonemura N, Hirata A, Tanihara $\mathrm{H}$, et al. Coinduction of nitric oxide synthase and arginine metabolic enzymes in endotoxininduced uveitis rats. Exp Eye Res (2002) 75(6):659-67. doi:10.1006/ exer.2002.2062

12. Louis CA, Reichner JS, Henry WL Jr, Mastrofrancesco B, Gotoh T, Mori $\mathrm{M}$, et al. Distinct arginase isoforms expressed in primary and transformed macrophages: regulation by oxygen tension. Am J Physiol (1998) 274(3 Pt 2):R775-82.

13. Modolell M, Corraliza IM, Link F, Soler G, Eichmann K. Reciprocal regulation of the nitric oxide synthase/arginase balance in mouse bone marrow-derived macrophages by TH1 and TH2 cytokines. Eur J Immunol (1995) 25(4):1101-4. doi: 10.1002/eji.1830250436

14. Morris SM Jr, Kepka-Lenhart D, Chen LC. Differential regulation of arginases and inducible nitric oxide synthase in murine macrophage cells. Am J Physiol (1998) 275(5 Pt 1):E740-7.

15. Barouch LA, Harrison RW, Skaf MW, Rosas GO, Cappola TP, Kobeissi ZA, et al. Nitric oxide regulates the heart by spatial confinement of nitric oxide synthase isoforms. Nature (2002) 416(6878):337-9. doi:10.1038/416337a

16. Christianson DW. Arginase: structure, mechanism, and physiological role in male and female sexual arousal. Acc Chem Res (2005) 38(3):191-201. doi:10.1021/ ar040183k

17. Ashamiss F, Wierzbicki Z, Chrzanowska A, Scibior D, Pacholczyk M, Kosieradzki M, et al. Clinical significance of arginase after liver transplantation. Ann Transplant (2004) 9(3):58-60.

18. Kim NN, Cox JD, Baggio RF, Emig FA, Mistry SK, Harper SL, et al. Probing erectile function:
S-(2-boronoethyl)-L-cysteine binds to arginase as a transition state analogue and enhances smooth muscle relaxation in human penile corpus cavernosum. Biochemistry (2001) 40(9):2678-88. doi:10.1021/ bi002317h

19. Ricky Baggio DE, Kanyo ZF, Carroll PJ, Cavalli C, Ash DE, Christianson DW. Inhibition of $\mathrm{Mn} 2+2$-arginase by borate leads to the design of a transition state analogue inhibitor, 2(S)-amino-6boronohexanoic acid. J Am Chem Soc (1997) 119(34):8107-8. doi:10. 1021/ja971312d

20. Kanyo ZF, Scolnick LR, Ash DE, Christianson DW. Structure of a unique binuclear manganese cluster in arginase. Nature (1996) 383(6600):554-7. doi:10.1038/383554a0

21. Di Costanzo L, Sabio G, Mora A, Rodriguez PC, Ochoa AC, Centeno F, et al. Crystal structure of human arginase I at 1.29-A resolution and exploration of inhibition in the immune response. Proc Natl Acad Sci U S A (2005) 102(37):13058-63. doi:10.1073/pnas.0504027102

22. Cama E, Colleluori DM, Emig FA, Shin H, Kim SW, Kim NN, et al. Human arginase II: crystal structure and physiological role in male and female sexual arousal. Biochemistry (2003) 42(28):8445-51. doi:10. 1021/bi034340j

23. Baggio R, Emig FA, Christianson DW, Ash DE, Chakder S, Rattan S. Biochemical and functional profile of a newly developed potent and isozyme-selective arginase inhibitor. J Pharmacol Exp Ther (1999) 290(3):1409-16.

24. Cox JD, Kim NN, Traish AM, Christianson DW. Arginase-boronic acid complex highlights a physiological role in erectile function. Nat Struct Biol (1999) 6(11):1043-7. doi:10. 1038/14929

25. Shin H, Cama E, Christianson DW. Design of amino acid aldehydes as transition-state analogue inhibitors of arginase. J Am Chem Soc (2004) 126(33):10278-84. doi: 10.1021/ja047788w

26. Colleluori DM, Ash DE. Classical and slow-binding inhibitors of human type II arginase. Biochemistry (2001) 40(31):9356-62. doi:10. 1021/bi010783g

27. Cama E, Pethe S, Boucher JL, Han S, Emig FA, Ash DE, et al. Inhibitor coordination interactions in the binuclear manganese cluster of arginase. Biochemistry (2004) 43(28):8987-99. doi:10. 1021/bi0491705
28. Boucher JL, Custot J, Vadon S, Delaforge M, Lepoivre M, Tenu JP, et al. $\mathrm{N}$ omega-hydroxyl-L-arginine, an intermediate in the L-arginine to nitric oxide pathway, is a strong inhibitor of liver and macrophage arginase. Biochem Biophys Res Commun (1994) 203(3):1614-21. doi: 10.1006/bbrc. 1994.2371

29. Boucher JL, Moali C, Tenu JP. Nitric oxide biosynthesis, nitric oxide synthase inhibitors and arginase competition for Larginine utilization. Cell $\mathrm{Mol}$ Life Sci (1999) 55(8-9):1015-28. doi:10.1007/s000180050352

30. Tenu JP, Lepoivre M, Moali C, Brollo M, Mansuy D, Boucher JL. Effects of the new arginase inhibitor $\mathrm{N}$ (omega)-hydroxy-norL-arginine on NO synthase activity in murine macrophages. Nitric Oxide (1999) 3(6):427-38. doi:10. 1006/niox.1999.0255

31. Cox JD, Cama E, Colleluori DM, Pethe S, Boucher JL, Mansuy $\mathrm{D}$, et al. Mechanistic and metabolic inferences from the binding of substrate analogues and products to arginase. Biochemistry (2001) 40(9):2689-701. doi:10. 1021/bi002318+

32. Shemyakin A, Kovamees O, Rafnsson A, Bohm F, Svenarud P, Settergren M, et al. Arginase inhibition improves endothelial function in patients with coronary artery disease and type 2 diabetes mellitus. Circulation (2012) 126(25):2943-50. doi:10.1161/ CIRCULATIONAHA.112.140335

33. Van Zandt MC, Whitehouse DL, Golebiowski A, Ji MK, Zhang $\mathrm{M}$, Beckett RP, et al. Discovery of (R)-2-amino-6-borono-2-(2(piperidin-1-yl)ethyl)hexanoic acid and congeners as highly potent inhibitors of human arginases I and II for treatment of myocardial reperfusion injury. J Med Chem (2013) 56(6):2568-80. doi:10.1021/ jm $400014 \mathrm{c}$

34. Ilies M, Di Costanzo L, Dowling DP, Thorn KJ, Christianson DW. Binding of alpha,alpha-disubstituted amino acids to arginase suggests new avenues for inhibitor design. $J$ Med Chem (2011) 54(15):5432-43. doi:10.1021/jm200443b

35. Golebiowski A, Paul Beckett R, Van Zandt M, Ji MK, Whitehouse D, Ryder TR, et al. 2-Substituted-2amino-6-boronohexanoic acids as arginase inhibitors. Bioorg $\mathrm{Med}$ Chem Lett (2013) 23(7):2027-30. doi:10.1016/j.bmcl.2013.02.024

36. Woo A, Min B, Ryoo S. Piceatannol3'-O-beta-D-glucopyranoside as an active component of rhubarb activates endothelial nitric oxide synthase through inhibition of arginase activity. Exp Mol Med (2010) 42(7): 524-32. doi:10.3858/emm.2010.42. 7.053

37. Kim SW, Cuong TD, Hung TM, Ryoo S, Lee JH, Min BS. Arginase II inhibitory activity of flavonoid compounds from Scutellaria indica. Arch Pharm Res (2013) 36(8): 922-6. doi:10.1007/s12272-0130125-3

38. Matsuda H, Morikawa T, Toguchida I, Park JY, Harima S, Yoshikawa M. Antioxidant constituents from rhubarb: structural requirements of stilbenes for the activity and structures of two new anthraquinone glucosides. Bioorg Med Chem(2001) 9(1):41-50. doi:10.1016/S09680896(00)00215-7

39. Woo A, Shin W, Cuong TD, Min B, Lee JH, Jeon BH, et al. Arginase inhibition by piceatannol-3'-O-beta-Dglucopyranoside improves endothelial dysfunction via activation of endothelial nitric oxide synthase in ApoE-null mice fed a highcholesterol diet. Int $\mathrm{J} \mathrm{Mol} \mathrm{Med}$ (2013) 31(4):803-10. doi:10.3892/ ijmm.2013.1261

40. De Vriese AS, Verbeuren TJ, Van de Voorde J, Lameire NH, Vanhoutte PM. Endothelial dysfunction in diabetes. $\mathrm{Br} J$ Pharmacol (2000) 130(5):963-74. doi:10.1038/ sj.bjp. 0703393

41. Egan JM, Henderson TE, Bernier M. Arginine enhances glycogen synthesis in response to insulin in 3T3L1 adipocytes. Am J Physiol (1995) 269(1 Pt 1):E61-6.

42. Kashyap SR, Lara A, Zhang R, Park YM, DeFronzo RA. Insulin reduces plasma arginase activity in type 2 diabetic patients. Diabetes Care (2008) 31(1):134-9. doi:10. 2337/dc07-1198

43. Salimuddin, Upadhyaya KC, Baquer NZ. Effects of vanadate on expression of liver arginase in experimental diabetic rats. IUBMB Life (1999) 48(2):237-40. doi:10.1080/ 152165499307297

44. Wu G, Meininger CJ. Impaired arginine metabolism and NO synthesis in coronary endothelial cells of the spontaneously diabetic BB rat. Am J Physiol (1995) 269(4 Pt 2):H1312-8

45. Bjelakovic G, Sokolovic D, Ljiljana S, Kocic G, Jevtovic T, Stojanovic I, et al. Arginase activity and magnesium levels in blood of children with diabetes mellitus. $J$ Basic Clin Physiol Pharmacol (2009) 
20(4):319-34. doi:10.1515/JBCPP. 2009.20.4.319

46. Salimuddin, Upadhyaya KC, Raju J, Baquer NZ. Modulation of mRNA levels of liver arginase by insulin and vanadate in experimental diabetes. Indian J Biochem Biophys (1999) 36(2):125-8.

47. Stickings P, Mistry SK, Boucher JL, Morris SM, Cunningham JM. Arginase expression and modulation of IL-lbeta-induced nitric oxide generation in rat and human islets of Langerhans. Nitric Oxide (2002) 7(4): 289-96. doi:10.1016/S10898603(02)00122-2

48. Eto M, Kozai T, Cosentino F, Joch $H$, Luscher TF. Statin prevents tissue factor expression in human endothelial cells: role of Rho/Rho-kinase and Akt pathways. Circulation (2002) 105(15):1756-9. doi:10.1161/01.CIR.0000015465. 73933.3B

49. Colhoun HM, Betteridge DJ, Durrington PN, Hitman GA, Neil
HA, Livingstone SJ, et al. Primary prevention of cardiovascular disease with atorvastatin in type 2 diabetes in the Collaborative Atorvastatin Diabetes Study (CARDS): multicentre randomised placebocontrolled trial. Lancet (2004) 364(9435):685-96. doi:10.1016/ S0140-6736(04)16895-5

50. Romero MJ, Platt DH, Tawfik HE, Labazi M, El-Remessy AB, Bartoli M, et al. Diabetes-induced coronary vascular dysfunction involves increased arginase activity. Circ Res (2008) 102(1):95-102. doi:10.1161/CIRCRESAHA.107. 155028

51. Beleznai T, Feher A, Spielvogel D, Lansman SL, Bagi Z. Arginase 1 contributes to diminished coronary arteriolar dilation in patients with diabetes. Am J Physiol Heart Circ Physiol (2011) 300(3): H777-83. doi:10.1152/ajpheart. 00831.2010

52. Khallou-Laschet J, Varthaman A, Fornasa G, Compain C, Gaston
AT, Clement M, et al. Macrophage plasticity in experimental atherosclerosis. PLoS ONE (2010) 5(1): e8852. doi:10.1371/journal.pone. 0008852

53. Mills CD. M1 and M2 macrophages: oracles of health and disease. Crit Rev Immunol (2012) 32(6):463-88. doi:10.1615/CritRevImmunol.v32. i6.10

54. Wynn TA, Barron L. Macrophages: master regulators of inflammation and fibrosis. Semin Liver Dis (2010) 30(3):245-57. doi:10.1055/s-00301255354

55. Santhanam L, Christianson DW, Nyhan D, Berkowitz DE. Arginase and vascular aging. $J$ Appl Physiol (2008) 105(5): 1632-42. doi:10.1152/japplphysiol. 90627.2008

Conflict of Interest Statement: The authors declare that the research was conducted in the absence of any commercial or financial relationships that could be construed as a potential conflict of interest.

Received: 18 May 2013; paper pending published: 12 August 2013; accepted: 29 August 2013; published online: 17 September 2013.

Citation: Steppan J, Nyhan D and Berkowitz DE (2013) Development of novel arginase inhibitors for therapy of endothelial dysfunction. Front. Immunol. 4:278. doi: 10.3389/fimmu.2013.00278 This article was submitted to Inflammation, a section of the journal Frontiers in Immunology.

Copyright (C) 2013 Steppan, Nyhan and Berkowitz. This is an open-access article distributed under the terms of the Creative Commons Attribution License (CC $B Y)$. The use, distribution or reproduction in other forums is permitted, provided the original author(s) or licensor are credited and that the original publication in this journal is cited, in accordance with accepted academic practice. No use, distribution or reproduction is permitted which does not comply with these terms. 